ments in medicine, where the simplified image of the caring country doctor with his black bag was replaced with images of medical teams employing modern scientific resources in intensive care units and transplant centres. Moral issues concerning benefit and harm, which were once considered obvious and noncontroversial, became challenging when viewed against a social background wherein greater emphasis was placed upon respect for the individual as a decision maker. Thus questions about justice and the meaning of life and death, long debated by lawyers, philosophers and theologians, took on a practical aspect within the context of new scientific medicine.

Jonsen examines the issues which generated most concern in the postwar years, such as human experimentation, genetic engineering, termination of life-sustaining treatment, and problems related to the new reproductive technologies. These topics occupy the five central chapters of the book, where each one is situated in its historic context and its treatment in bioethical discourse is examined. It is worth noting that these historical studies are not confined to the forty years of bioethics which is the intended scope of the book. Jonsen recognises that many of the philosophical and theological problems have a long ancestry and his excursions into their historical origins will be appreciated by the contemporary reader. There is also a wealth of information concerning the early conferences and commissions dealing with bioethical issues, together with the arguments of some of the major figures in bioethics. As a prominent member of the US President's Commission Jonsen is particularly informative with regard to the debates which resulted in several of its influential reports.

Many of Jonsen's historical and ethical surveys testify to the immorality of the unrestrained application of science to medicine throughout this century, from abuses in research on human subjects to the infamous pursuit of eugenics, the early years of organ transplantation, attitudes towards the dying and the dead, and the controversies generated by scientific involvement in human reproduction. The emergence of bioethics is consequently an expression of public concern.

Towards the end of the book there is a chapter which examines bioethics as an academic discipline and the search for a general theory for bioethics; a chapter on bioethics as a form of public discourse which is carried out by many people outside of the academy, and a final chapter which locates the origin and evolution of bioethics in the Americal liberal tradition. By "liberal tradition" Jonsen means the ethos in which the US civil rights movement emerged and the opposition to American involvement in the war in South East Asia, which gave expression to concern for the rights of individuals and a distrust of authority. This would suggest that bioethics is primarily an American phenomenon, and whilst the emergence of bioethics outside the US is covered briefly, that is a subject which lies beyond the scope of this book.

DAVID LAMB

University of Birmingham

\section{Rationing: Talk and Action in Health Care}

\section{Edited by Bill New, London, BMJ \\ Publishing Group, 1997, 261 pages, $£ 25.00$.}

Rationing, a word destined to bring shivers down the spines of our political masters, despite the general agreement of all who work within the National Health Service (NHS) and the vast majority of the public that, however one may choose to label it, the central issue is about how choices are to be made under conditions of scarce resources. The many authors come from within the service or from policy institutes, and include clinicians, economists and analysts. Professional philosophers are less well represented. There is little to be found in the way of underpinning assertions based on ethical theory, and where attempts are made, the results are not altogether successful.

The articles cover the entire range of issues that have attracted the interest of those working in the field. I particularly enjoyed the debate between Alan Williams and John Grimley Evans on age as a criterion for rationing, and between Tony Culyer and John Harris on the objectives of the NHS. By far the most original article, I thought, was that by Len Doyal and Joanna Coast, who discuss the extent to which rationing should be made explicit at the different levels of decision making. It is so much a part of the culture of the NHS that decision making should be explicit, that counterargument to suggest that plicitness might have a disutility of own or that it might not best serve the interests and welfare of individut patients was to me quite refreshiris. Many clinicians have intuitively alw $\mathrm{s}$ believed this and have not been persuaded by the arguments for plicitness and public participatio. They will find some comfort $\mathrm{m}$ the more formal articulation of their views, not only by Coast, a hea economist, but by commentators sueh as David Mechanic, a sociologist, a $\overrightarrow{a d}$ David Hunter, a policy analyst, in $\mathbb{R}$ referenced literature.

The second section of the book, which debates the issues described above, was the most successful and enjoyable. The first section, said of deal with "the theoretical policy $\mathbb{R}$ bate", was less successful and in my view did not achieve its stated aint. Nevertheless there is much common sense and realism to be found in Bpll New's chapter, written on behalf $\mathbb{T}^{\mathrm{f}}$ the Rationing Agenda (RAG), andक्कूn Chris Heginbotham's robust counter to the arguments of the idiosyncratic Anti-Rationing Group, in his chapfor on the inevitability of rationing the NHS. I was disappointed to learnothat a consensus from the RAG, that method of financing the NHS show be based on general taxation, hAld emerged without any discussion as the reasons for that consensus, without an ethical dissection of the benefits and risks of a mixed economy in the funding of health services. The central importance of equity or fairness as a guiding value in the delive्सy of health services can be accepted by most if not everyone, but there hass been little debate as to whether managed introduction of a privafpublic mix will lead to greater or lesser degrees of equity in a social enviroment where greater accessibility to health information and consumerisfon predominate, and where technical ad scientific developments are likely noo escalate even further the costs of health care.

In the third section useful summes ries are given of practical attempts to apply rationing in real clinical siturations. Experiences from other cout tries are always informative, and t information from both Sweden and New Zealand proves to be no excep tion. The attempt by David Ebbs ao d his colleagues to provide a framewougk for rationing in a general practice s]ting is a brave attempt, but I am not persuaded that there are no significant 
conflicts of interest between the general practitioner's (GP) role as an allocator of scarce resources and as the patient's agent. Indeed, the article declares that "the partnership may not always be able to pursue the best interests of every patient in every circumstance". That this should be regarded as the partnership's responsibility is a direct consequence of fundholding; that it is the responsibility of someone or some Institution in society is inevitable. It is whether the GP can ethically make these choices that I question, and the question is not answered convincingly in the article.

This book is truly an example of talk and action $\mathrm{m}$ the delivery of health care. As such it provides a good lead into the current thinking of those involved in health services, and can be thoroughly recommended. What it does not do - but perhaps that was not its purpose - is to provide a satisfactory and systematic account of rationing as it relates to ethical theory. Perhaps the subject is too difficult. I believe Isaiah Berlin pointed the way by insisting that the values which we hold in society are truly incommensurable. There was a hint of this in Rudolf Klein's piece, where he argues against the establishment of a defined package of health care to be delivered by the NHS citing that "no consensus exists about the principles or criteria that should be used in designing such a package".

\section{RON ZIMMERN}

Director, Public Health Genetics Unit Strangeways Research Laboratory Worts Causeway, Cambridge

\section{Books: information and orders}

If you wish to order or require further information regarding the titles reviewed here, please write or telephone the BMJ Bookshop, PO Box 295, London WC1H 9JR. Tel: 0171383 6244; fax: 0171383 6455; Internet: www.bmjbookshop.com; email: orders@bmjbookshop.com. European customers should add 15 per cent for postage and packing, other overseas customers should add $30 \%$. Payment can be made by cheque in sterling drawn on a UK bank or by credit card (Mastercard,Visa, or American Express, stating card number, expiry date and full name. (The price and availabality are occasionally subject to revision by the publishers.)

(1)

